\title{
Bufalin suppresses endometriosis progression by inducing pyroptosis and apoptosis
}

\author{
Yeon Jean Cho',2,*, Jiyeun E Lee',*, Mi Jin Park', Bert W O'Malley1,3 and Sang Jun Han 1,3 \\ 'Department of Molecular and Cellular Biology, Baylor College of Medicine, Houston, Texas, USA \\ 2Department of Obstetrics and Gynecology, Dong-A University, College of Medicine, Busan, Republic of Korea \\ ${ }^{3}$ Center for Reproductive Medicine, Baylor College of Medicine, Houston, Texas, USA \\ Correspondence should be addressed to S J Han: sjhan@bcm.edu \\ *(Y J Cho and J Lee contributed equally to this work)
}

\section{Abstract}

The steroid receptor coactivator (SRC)-1 isoform/estrogen receptor (ER)- $\beta$ axis has an essential role in endometriosis progression. In this context, therefore, bufalin was employed as a 'tool compound' to evaluate inhibitors of SRC in alternative endometriosis treatment. Bufalin effectively suppressed the growth of primary human endometrial stroma cells isolated from endometriosis patients compared to women without endometriosis and immortalized human endometrial epithelial and stromal cells expressing the SRC-1 isoform compared to their parental cells in vitro. In vivo, compared to the vehicle, bufalin treatment significantly suppressed the
Key Words
- endometriosis
- steroid receptor coactivator 1 isoform
- estrogen receptor $\beta$
- bufalin
- apoptosis
- pyroptosis growth of endometriotic lesions in mice with surgically induced endometriosis because bufalin disrupted the functional axis of SRC-1 isoform/ER $\beta$ by increasing SRC-1 isoform protein stability, hyperactivating the transcriptional activity of the SRC-1 isoform and degrading the ER $\beta$ protein by proteasome $26 \mathrm{~S}$ subunit, non-ATPase 2 in endometriotic lesions. Bufalin treatment elevated the apoptosis signaling in epithelial cells of endometriotic lesions. In stromal cells of endometriotic lesions, bufalin treatment increased the levels of pyroptosis markers (caspase 1 and the active form of interleukin $1 \beta$ ) and reduced proliferation. In addition, bufalin treatment increased the expression levels of endoplasmic reticulum-stress (ERS) markers (PKR-like ER kinase, protein disulfide isomerase and binding immunoglobulin) in endometriotic lesions. Collectively, the bufalin-induced disruption of the SRC-1 isoform/ER $\beta$ axis might induce apoptosis, pyroptosis and ERS signaling in endometriotic lesions, causing the suppression of endometriosis. Therefore, future generations of SRC-modulators could be employed as an alternative medical approach for endometriosis treatment.

\section{Introduction}

As an estrogen-dependent pro-inflammatory disease, endometriosis is defined as the colonization and growth of endometrial tissues at anatomic sites outside of the uterine cavity, primarily in the pelvic peritoneum and ovaries (Bulun 2009). Up to 10\% of reproductive-aged women in the United States chronically suffer from symptoms of endometriosis, which include pelvic pain, infertility, menstrual cycle abnormalities and increased 
risk of certain cancers, such as ovarian, breast and skin cancers (Vercellini et al. 2014, Farland et al. 2016, 2017, Brilhante et al. 2017, Poole et al. 2017).

Due to the severe chronic morbidity associated with this gynecological disorder, a number of past studies have attempted to identify the distinguishing molecular features of the endometriotic lesion with a view to developing more effective prognostic, diagnostic and/or treatment strategies in the clinical management of this debilitating disease (Bedaiwy et al. 2017). Despite such efforts, many of the current clinical treatments are not adequately effective at treating this disease and produce unacceptable side effects. For example, studies have shown that levels of prostaglandin E2 (PGE2), cyclooxygenase-2 (COX-2) and various cytokines are highly elevated in endometriotic tissue relative to the normal endometrium, supporting a heightened pro-inflammatory response as a major component of this disease (Hirata et al. 2011, Sacco et al. 2012). Therefore, selective COX-2 inhibitors are used as the conventional treatment for this disorder (Ebert et al. 2005). However, COX-2 selective inhibitors have gastrointestinal side effects, even though their side effects are much less severe than older non-steroidal antiinflammatory drugs (Ebert et al. 2005).

Similarly, it has been well established that increased concentrations of $17 \beta$-estradiol (E2) in endometriotic tissues arise from locally elevated levels of aromatase along with reduced activity of $17 \beta$-hydroxysteroid dehydrogenase- 2 (Bulun et al. 2010, Lamp et al. 2011). Therefore, along with the anti-inflammatory treatments described earlier, current endometriosis treatments also involve suppressing E2 levels through the use of gonadotropin-releasing hormone agonists, oral contraceptives, synthetic progestins and/or aromatase inhibitors (Goenka et al. 2017). However, many clinical reports have revealed that these systemic estrogen deficiency therapies cause infertility and confer harmful side effects in other estrogen target tissues, such as bone and brain.

Because of the unacceptable deficiencies cited earlier, there is clearly an urgent need to identify new molecular mechanisms that critically underpin the initiation and progression of endometriosis to develop more effective therapeutics that lack the side effects of current treatments. Interestingly, our prior study revealed that a steroid receptor coactivator (SRC)-1 isoform that is proteolytically cleaved from the full-length SRC- 1 by matrix metalloproteinase- 9 and estrogen receptor (ER) $\beta$ are specifically elevated in endometriotic tissues compared to the normal endometrium, and this SRC- 1 isoform/ER $\beta$ axis has an essential role in endometriosis progression because this axis prevents
TNF $\alpha$-mediated apoptosis and enhances inflammasomemediated inflammatory signaling in endometriotic lesions for their survival (Han et al. 2012, 2015). Collectively, these recent findings led us to hypothesize that the SRC-1 isoform/ER $\beta$ axis should be a new molecular therapeutic target for an alternative endometriosis treatment to enhance the specificity of endometriosis treatment and reduce the side effects of previous endometriosis treatments. Our previous studies defined small molecular inhibitors (SMIs), such as bufalin and gossypol, that diminished the activities and protein stabilities of SRCs and suppressed the growth of various cancer cells (Wang et al. 2011, 2014). These observations led us to investigate whether SMIs against SRCs could be employed to suppress endometriosis progression due to the crucial role of the SRC-1 isoform in endometriosis progression. Therefore, we here show that bufalin, one of the SMIs against SRCs, represents a new class of drugs that could be used to combat endometriosis based on its antagonistic role against the SRC- 1 isoform/ER $\beta$ axis in endometriotic lesions.

\section{Materials and methods}

\section{Mice}

Mice were housed in a pathogen-free animal facility under a standard 12-h light/12-h darkness cycle and were fed standard rodent chow and water. All animal experimentation was conducted in accordance with accepted standards of humane animal care. All animal care was controlled by the ethical regulations approved by the Institutional Animal Care and Use Committee at Baylor College of Medicine. Five-week-old normal (C57BL/6J) mice were purchased from Jackson Laboratory.

\section{Immortalized human endometrial cells}

Primary human endometrial stromal cells isolated from women with/without endometriosis (Han et al. 2012), immortalized human endometrial stromal cells (IHESCs) (Krikun et al. 2004), EMosis-CC/TERT1 (immortalized human endometriotic epithelial cells; IHEECs) (Bono et al. 2012) and HeLa cells were confirmed by Short Tandem Repeat profiling; these cells were not contaminated with mycoplasma.

\section{Generation of a lentivirus expressing the SRC-1 isoform}

The open reading frame of the SRC-1 isoform gene was cloned into a pCDH-pCMV vector using BamH1 and XhoI 
restriction enzymes. Next, 293T cells on a $100-\mathrm{cm}$ tissue culture dish were transfected with the pCDH-pCNV-SRC-1 isoform and Lenti-X packaging single shot (Clontech Laboratories). The virus-containing medium was collected at $48 \mathrm{~h}$ after transfection. The lentivirus titer was determined by Lenti-X GoStix (Clontech Laboratories).

\section{Generation of IHESCs and IHEECs that expressed the SRC-1 isoform}

IHEECs and IHESCs were cultured in a 10-cm dish. When the cell confluency reached $70 \%, 6 \mathrm{~mL}$ of new medium containing $64 \mu \mathrm{g}$ of polybrene was added, and then $2 \mathrm{~mL}$ of media containing lentivirus (MOI of approximately 2) was added. At 2 days after transduction, $2 \mu \mathrm{g} / \mathrm{mL}$ of puromycin was added to the media. The puromycinresistant cells were selected, and then the expression of the SRC-1 isoform in these cells was determined by Western blot analyses with SRC-1 antibody.

\section{MTS cell growth assay}

Primary human endometrial stromal cells isolated from women with/without endometriosis, IHEECs, IHEECs:SRC-1 ISO, IHESCs and IHESCs:SRC-1 ISO were inoculated into the wells of 96 -well plates $\left(1 \times 10^{4}\right.$ cells/ well). The next day, each cell line was treated with serially diluted bufalin $(0-800 \mathrm{nM})$ and vehicle as the control. After 2 days, $10 \mu \mathrm{L}$ of MTS reagent was added to each well. MTS-treated plates were incubated for 2 more hours. After that, the optical density of color in each well was measured at $490 \mathrm{~nm}$ in a microtiter plate reader.

\section{Surgically induced endometriosis}

Endometriosis in mice was surgically induced under aseptic conditions under anesthesia using a modified method as described previously (Cummings \& Metcalf 1995). Briefly, C57BL/6 mice were subjected to ovariectomy at six weeks old. After one week, the ovariectomized mice were implanted with a sterile, 60-day release pellet containing $0.36 \mathrm{mg}$ of $17-\beta$ estradiol (Innovative Research of America, Sarasota, FL, USA). Two days later, one uterine horn from each mouse was isolated under anesthesia. In a Petri dish containing warmed DMEM/F-12 supplemented with $100 \mathrm{U} / \mathrm{mL}$ penicillin and $100 \mu \mathrm{g} / \mathrm{mL}$ streptomycin, the uterine horns were longitudinally cut with a pair of scissors. Next, using a 2-mm dermal biopsy punch, one endometrial fragment was isolated and subsequently sutured to the mesenteric membrane attached to the intestine in the same mouse through a midline incision (7-0 braided polypropylene suture). In the case of shamtreated control mice, a suture was performed without endometrial tissue fragments. The abdominal incision was then closed with a 5-0 braided polypropylene suture in a continuous fashion. On day 21 after endometriosis challenge, the mice were killed, and the endometriotic lesions and eutopic endometria were carefully isolated from the surrounding tissue. Using the formula volume $\left(\mathrm{mm}^{3}\right)=0.52 \times$ width $\times$ length $\times$ height, the volumes of the endometriotic lesions were calculated.

\section{Bufalin treatment of endometriosis-induced mice}

Endometriosis was surgically induced as described earlier. Based on a previous study, we injected mice with $1 \mathrm{mg} / \mathrm{kg}$ of bufalin (Zhang et al. 2014). After endometriotic lesions were established (one week after endometriosis induction), the mice were randomly divided into two groups and then subcutaneously administered vehicle (as the control) or $1 \mathrm{mg} / \mathrm{kg}$ of bufalin daily for 21 days.

\section{Bufalin treatment of wild-type mice}

Female C57BL/6J (6 weeks old) were treated with $1 \mathrm{mg} / \mathrm{kg}$ of bufalin and vehicle as the control every day for 21 days. Two weeks before harvesting the uteri, mouse estrous cycles were determined using vaginal cytology (McLean et al. 2012). At the estrus cycle after 21-day drug treatment, uteri were isolated from mice treated with bufalin and vehicle.

\section{Fertility assay following bufalin treatment}

C57BL/6J female mice ( 8 weeks of age) were treated daily with vehicle and bufalin $(1.0 \mathrm{mg} / \mathrm{kg})$ for 21 days ( $n=3$ /group). Afterwards, each female mouse was paired with a wild-type male of proven fertility (1:1). The fertility was assessed by monitoring the litter size over a twomonth period.

\section{Western blot analyses}

Endometriotic tissues, human endometrial cells and transfected HeLa cells were washed with PBS solution and homogenized in a buffer containing $10 \mathrm{mM}$ Tris- $\mathrm{HCl}(\mathrm{pH}$ 7.4), $150 \mathrm{mM} \mathrm{NaCl}, 2.5 \mathrm{mM}$ EDTA and $0.5 \%$ Nonidet P-40 (vol/vol). Cellular debris was removed by centrifugation at $12,000 \mathrm{~g}$ for $15 \mathrm{~min}$ at $4^{\circ} \mathrm{C}$. The protein concentration was determined by Bradford's method using bovine serum 
albumin as the standard. Samples containing $10 \mu \mathrm{g}$ total proteins were subjected to $10 \%$ SDS-polyacrylamide gel electrophoresis. The separated proteins were then transferred onto a polyvinylidene difluoride membrane. Membranes were blocked overnight with 5\% skim milk $(\mathrm{wt} / \mathrm{vol})$ in phosphate-buffered saline with $0.1 \%$ Tween 20 (vol/vol). Primary antibodies against the following proteins were used: SRC-1 (ab10308; Abcam), tubulin (SC-9104; Santa Cruz Biotechnologies), ER $\alpha$ (SC-542; Santa Cruz Biotechnologies) and chicken anti-ER $\beta$ antibody 503 (Saji et al. 2000). Membrane-containing proteins were incubated with secondary horseradish peroxidase-tagged antibodies (Sigma), and the signals were visualized using an enhanced luminol-based substrate for horseradish peroxidase.

\section{Immunohistochemistry}

Immunostaining was performed with $10 \%$ neutralbuffered, formalin-fixed and paraffin-embedded sections of mouse tissue, as previously described (Han et al. 2005). For immunostaining, sections were dewaxed, rehydrated and boiled for $10 \mathrm{~min}$ in $10 \mathrm{mM}$ citrate buffer, $\mathrm{pH}$ 6.0. To reduce nonspecific binding of antibodies, sections were washed in PBS again and preincubated with 5\% BSA in PBS for $1 \mathrm{~h}$ at room temperature. Antibodies against PSMD2 (A303-854A-T; Bethyl Laboratories), UBA7 (ab133479, Abcam), Ki-67 (ab16667; Abcam), cleaved caspase 3 (9664; Cell Signal), caspase 1 (2225; Cell Signal), active form of Interleukin (IL)-1 $\beta$ (521875; Cell Signaling), PERK (5683; Cell Signal), PDI (3501; Cell signal) and BiP (3177; Cell Signal) were used. The specific antigens were visualized with the DAB substrate kit. The immunostaining intensity was quantified using the Image program, which was developed by the National Institutes of Health.

\section{TUNEL assay}

The TUNEL assay was conducted with a TACS.XL DAB In Situ Apoptosis Detection Kit and its protocol (Trevigen, Inc., Gaithersburg, MD, USA).

\section{Transfection and luciferase reporter gene assay}

Transfections with plasmids were performed using Lipofectamine 2000 reagent (Invitrogen) according to the manufacturer's instructions. HeLa cells were transfected with the indicated expression plasmids. For the determination of ER $\beta$ transcriptional activity, estradiol $\left(10^{-8} \mathrm{M}\right)$ was added to cells $24 \mathrm{~h}$ following transfection and incubated for another $24 \mathrm{~h}$. The cells were harvested, and the luciferase activity was determined and normalized against the total input protein.

\section{Statistical analyses}

Statistical analyses were performed by using Windows GraphPad Prism 5 (GraphPad Software). The data are expressed as the mean \pm S.E.M. Significance was assessed using an independent two-tailed Student's $t$-test. A $P$ value of less than 0.05 was considered statistically significant. N.S., nonspecific.

\section{Results}

Bufalin effectively inhibited the growth of primary human endometrial stromal cells isolated from endometriosis patients and immortalized human endometrial cells expressing the SRC- 1 isoform

Compared to levels in the normal endometrium, levels of the SRC-1 isoform are highly elevated in endometriotic tissues, and this isoform prevents TNF $\alpha$-induced apoptosis signaling in endometriotic lesions for their survival (Han et al. 2012). Therefore, targeting the SRC-1 isoform should reactivate $\mathrm{TNF} \alpha$-induced apoptosis in endometriotic lesions, killing them. To inhibit SRC activity, we previously identified SMIs that inhibited the function of SRCs. Bufalin, one of the SRC-SMIs, inhibited the intrinsic transcriptional activity of SRC- 1 and -3 and degraded their proteins in various cancer cells to suppress their growth (Wang et al. 2014). These observations led us to examine whether bufalin might suppress endometriosis progression by inhibiting the function of the SRC-1 isoform in endometriotic tissues.

To determine whether endometriotic tissues are more sensitive to bufalin compared to normal endometrium, we determined the growth pattern of primary human endometrial stromal cells isolated from women with/ without endometriosis upon bufalin treatment (Han et al. 2012). Bufalin effectively inhibited the growth of primary human endometrial stromal cells from endometriosis patients compared to those isolated from women without endometriosis (Fig. 1A). Therefore, endometriotic cells were more sensitive to bufalin treatment than normal endometrial cells.

In addition to primary human endometrial cells, we employed IHESCs and IHEECs as human endometrial epithelial and stromal cell lines, respectively, because IHESCs are karyotypically, morphologically and 

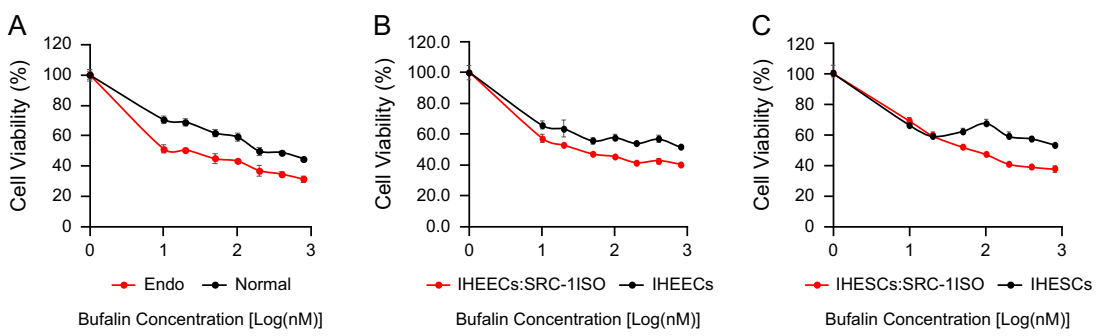

\section{Figure 1}

Bufalin inhibited the growth of primary human endometrial stromal cells isolated from endometriosis patients and immortalized human endometrial cells expressing the SRC-1 isoform. (A) The growth patterns of primary human endometrial stromal cells isolated from women with (Endo) and without (Normal) endometriosis were determined at different concentrations of bufalin $(0,10,20,50,100,200,400$ and $800 \mathrm{nM})$ for $48 \mathrm{~h}$ of treatment, by using the MTS cell growth assay. (B) The growth patterns of IHEECs expressing the SRC-1 isoform (IHEECs:SRC-1 ISO) and their parental cells were determined at different concentrations of bufalin for $48 \mathrm{~h}$, by using the MTS cell growth assay. (C) The growth patterns of IHESCs expressing the SRC-1 isoform (IHESCS:SRC-1 ISO) and their parental cells were determined at different concentrations of bufalin for $48 \mathrm{~h}$, by using the MTS cell growth assay. Data are presented as the means \pm S.E.M.

phenotypically similar to the primary parent cells (Krikun et al. 2004) and because IHEECs also retain the normal functions and characteristics of the primary cells (Kyo et al. 2003). To determine the role of the SRC-1 isoform in bufalin-mediated suppression of endometriotic cells, we generated recombinant IHEECs and IHESCs that stably expressed the SRC-1 isoform (IHEECs:SRC-1 ISO and IHESC:SRC-1 ISO) using a lentivirus containing the SRC-1 isoform gene expression unit. The growth of IHESCs:SRC-1 ISO and IHEECS:SRC-1 ISO was significantly reduced by bufalin treatment compared to their parental cells (Fig. 1B and C). Therefore, the overexpression of the SRC-1 isoform in human endometrial epithelial and stromal cells increased the sensitivity against bufalin.

\section{Bufalin suppressed the growth of endometriotic lesions in mice with endometriosis in vivo}

We next examined whether bufalin suppresses the growth of endometriotic lesions in mice with surgically induced endometriosis in vivo because of the essential role of the SRC-1 isoform in endometriosis progression. To address this issue, endometriosis was surgically induced in $\mathrm{C} 57 \mathrm{BL} / 6 \mathrm{~J}$ mice using an autotranslation method. After the establishment of endometriotic lesions in mice (at one week after endometriosis induction), mice with endometriosis were randomly divided two groups and then injected with bufalin $(1.0 \mathrm{mg} / \mathrm{kg}$, daily, $n=4 /$ group) or with vehicle for the control ( $n=4 /$ group). To determine the effect of bufalin in endometriosis progression, we isolated endometriotic lesions from each drug-treated mouse with endometriosis and then determined the volume of the endometriotic lesions. Compared to the vehicle, bufalin treatment reduced the volume of the endometriotic lesions by 14 -fold $(P=0.009)$ (Fig. 2A). Therefore, bufalin treatment significantly suppressed the growth of endometriotic lesions in mice with endometriosis in vivo.

Since the SRC-1 isoform/ER $\beta$ axis plays a crucial role in endometriosis progression, we next examined whether bufalin treatment disrupts this SRC-1 isoform/ $\operatorname{ER} \beta$ functional axis in endometriotic lesions to suppress their growth. Western blot analysis revealed that compared to the vehicle, bufalin treatment increased SRC-1 isoform protein levels by 2.7 -fold $(P=0.005)$ in endometriotic lesions (Fig. 2B). To validate this bufalin-induced elevation of SRC-1 isoform levels in endometriotic lesions, IHESCs:SRC-1 ISO cells were treated with bufalin $(0,5$ and $20 \mathrm{nM})$ for 24 or $48 \mathrm{~h}$. We found that $20 \mathrm{nM}$ bufalin treatment, compared with the vehicle, elevated the SRC-1 isoform protein levels by 2.4-fold in IHESCs:SRC-1 ISO with 48-h treatment (Fig. 2C). To define the effect of bufalin on full-length SRC-1, endogenous SRC-1 levels in IHESCs treated with bufalin were determined by Western blot analyses. In contrast to the results for the SRC-1 isoform, $20 \mathrm{nM}$ bufalin treatment, compared with the vehicle, reduced the levels of full-length SRC-1 by 5.0-fold in IHESCs with 48-h treatment (Fig. 2D). The bufalin-induced degradation of full-length SRC-1 in various cancer cells was also reported in our previous study (Wang et al. 2014). Therefore, bufalin increased SRC-1 isoform protein levels but reduced the full-length SRC-1 protein levels in endometriotic tissues.

In addition to the SRC- 1 isoform, $\operatorname{ER} \beta$ also has an essential role in endometriosis progression. Therefore, we determined whether bufalin also affects the ER $\beta$ axis in endometriotic lesions. In contrast to the results for the SRC-1 isoform, however, bufalin treatment, compared to 
A

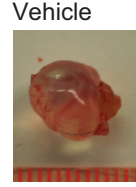

Bufalin

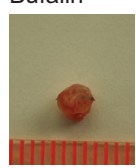

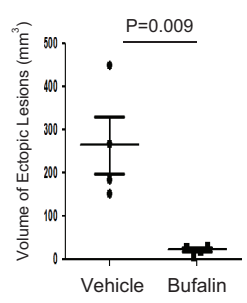

B

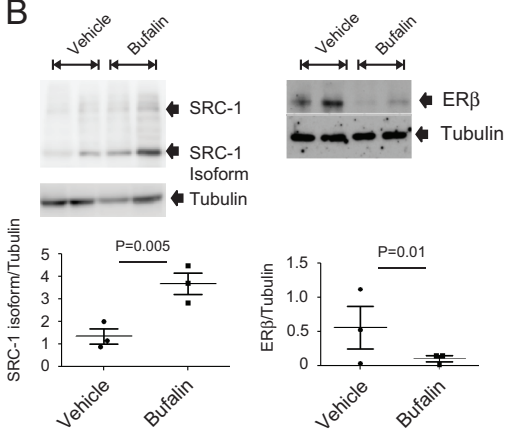

C

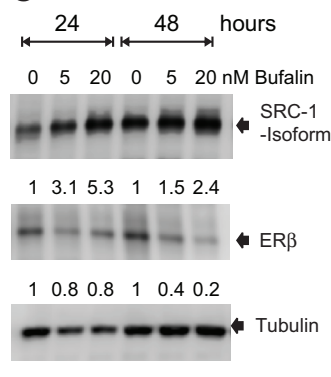

D

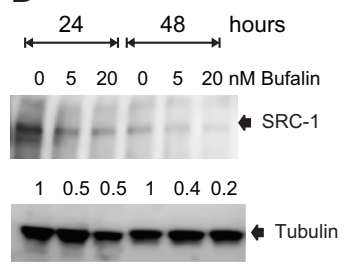

Figure 2

Bufalin suppressed the growth of endometriotic lesions in mice with endometriosis. (A) Endometriotic lesions were isolated from mice with surgically induced endometriosis treated with $1.0 \mathrm{mg} / \mathrm{kg}$ bufalin and the vehicle as the control ( $n=4$ mice for each group). The volume of each endometriotic lesion was determined by the formula volume $\left(\mathrm{mm}^{3}\right)=0.52 \times$ width $\times$ length $\times$ height. (B) Protein levels of the SRC- 1 isoform, ER $\beta$ and tubulin were determined in endometriotic lesions treated with bufalin ( $1 \mathrm{mg} / \mathrm{kg}$ ) or vehicle by Western blot analysis ( $n=3 \mathrm{mice}$ for each group). (C) IHESCs:SRC-1 ISO cells were treated with 5 and $20 \mathrm{nM}$ bufalin for 24 and $48 \mathrm{~h}$, and then protein levels of the SRC-1 isoform, ER $\beta$ and tubulin were determined by Western blot analysis. (D) IHESCs were treated with 5 and $20 \mathrm{nM}$ bufalin for 24 and $48 \mathrm{~h}$, and then protein levels of the full-length SRC-1 isoform and tubulin were determined by Western blot analysis. Data are presented as the means \pm S.E.M. and $P$ value (Student's $t$-test).

the vehicle, reduced ER $\beta$ protein levels by 7.2 -fold $(P=0.01)$ in endometriotic lesions (Fig. 2B). In addition to those of endometriotic lesions, ER $\beta$ levels in IHESCs:SRC-1 ISO were reduced by 5.0 -fold by $20 \mathrm{nM}$ bufalin at 48 -h treatment compared with the levels after vehicle treatment (Fig. 2C). Therefore, bufalin treatment disrupted the SRC-1 isoform/ ER $\beta$ axis by increasing SRC-1 isoform protein levels, decreasing ER $\beta$ protein levels in endometriotic lesions, and then suppressing endometriosis progression.

\section{Bufalin increased the intrinsic transcriptional activity of the SRC- 1 isoform but not the ER $\beta$ activity}

We asked whether bufalin also affects the intrinsic transcriptional activity of the SRC-1 isoform in addition to protein levels because bufalin inhibits the intrinsic transcriptional activity of full-length SRC-1 (Wang et al. 2014). To address this issue, we generated a mammalian expression vector for the chimeric SRC-1 isoform protein fused to the Gal4 DNA-binding domain (pBID-SRC-1 isoform) and then transiently transfected it into HeLa cells along with a pG5 luciferase reporter containing Gal4 DNA-binding elements. Compared to the empty expression vector control, the SRC-1 isoform had an intrinsic transcriptional activity, and its transcriptional activity was elevated by $5 \mathrm{nM}$ bufalin treatment (3-fold, $P=0.005$ ) compared to the vehicle (Fig. 3A). Collectively, bufalin hyperactivated the SRC-1 isoform function in endometriotic lesions by stabilizing the SRC-1 isoform protein, stimulating its transcriptional activity.

We next determined the effect of bufalin on the intrinsic transcriptional activity of ER $\beta$ using an
ER $\beta /$ Estrogen Response Element luciferase assay system in HeLa cells. Compared with the vehicle, estrogen treatment significantly enhanced the intrinsic transcriptional activity of ER $\beta$ (Fig. 3B). However, compared to the vehicle, bufalin treatment did not affect the E2-induced transcriptional activity of ER $\beta$ (Fig. 3B). Therefore, bufalin treatment decreased the protein levels of ER $\beta$ but did not inhibit its transcriptional activity in endometriotic lesions.
A

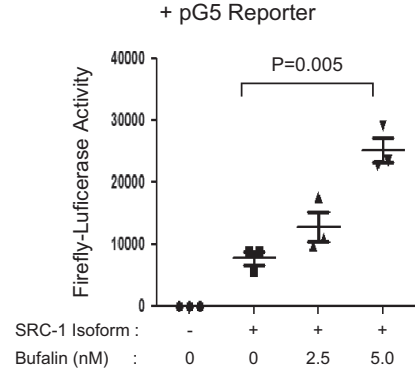

B

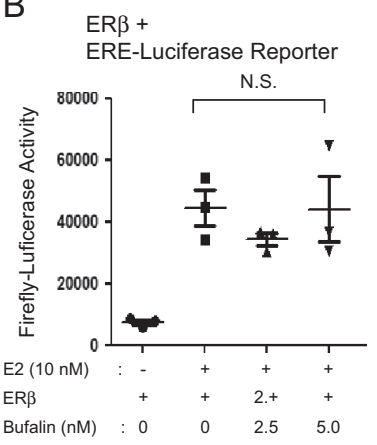

Figure 3

Bufalin stimulated the intrinsic transcriptional activity of the SRC-1 isoform. (A) HeLa cells were transfected with PBID-SRC-1 isoform and pG5 reporter vectors and then treated with $0,2.5$ or $5.0 \mathrm{nM}$ bufalin for $48 \mathrm{~h}$. The luciferase activity in HeLa cells treated with different doses of bufalin was determined to define the intrinsic transcriptional activity of the SRC-1 isoform upon bufalin treatment. (B) HeLa cells were transfected with an ER $\beta$ expression vector and ERE-luciferase reporter. To stimulate ER $\beta$ activity, HeLa cells were treated with estradiol $(10 \mathrm{nM})$ plus $0,2.5$ or $5.0 \mathrm{nM}$ bufalin treatment for $48 \mathrm{~h}$. The luciferase activity in HeLa cells treated with different doses of bufalin was determined to define the intrinsic transcriptional activity of the ER $\beta$ upon bufalin treatment. Data are presented as the means \pm S.E.M. and $P$ value (Student's $t$-test). 


\section{Journal of Endocrinology \\ Y J Cho, J E Lee et al.

Y J \\ Bufalin degraded ER $\beta$ protein via the proteasome 26S subunit, non-ATPase 2 (PSMD2) in endometriotic tissues}

How does bufalin degrade ER $\beta$ in endometriotic lesions? To determine the molecular function of ER $\beta$ in endometriosis progression, we isolated the ER $\beta$-containing complex from endometriotic lesions using immunoprecipitation and then identified all protein components co-precipitated with ER $\beta$ (Han et al. 2015). Interestingly, these data revealed that several proteasome components, such as proteasome $26 \mathrm{~S}$ Subunit, non-ATPase 2 (PSMD2) and ubiquitin-like modifier activating enzyme 7 (UBA7), were specifically co-precipitated with ER $\beta$ from endometriotic lesions. This observation led us to investigate the potential roles of PSMD2 and UBA7 in bufalin-induced ER $\beta$ protein degradation in endometriotic tissues. To validate this hypothesis, we measured the protein levels of PSMD2 and UBA7 in endometriotic lesions treated with bufalin vs vehicle using immunohistochemistry (IHC). Bufalin treatment increased the levels of PSMD2 and UBA7 in both epithelial and stromal cells from endometriotic lesions compared to vehicle-treated endometriotic lesions (Fig. 4A and B).

We next examined whether the increased quantities of PSMD2 and UBA7 degraded ER $\beta$ proteins in endometriotic lesions. To address this issue, HeLa cells
Bufalin suppresses

endometriosis were cotransfected with expression vectors containing $E R \beta$ plus PSMD2 or ER $\beta$ plus UBA7. An empty expression vector was also cotransfected into HeLa cells with $E R \beta$ expression vector as the control. The overexpression of PSMD2 decreased ER $\beta$ protein levels by 2.5 -fold in $\mathrm{HeLa}$ cells compared with the empty vector control (Fig. 4C). However, the overexpression of UBA7 protein did not degrade ER $\beta$ protein compared to the empty vector control (Fig. 4C). Therefore, elevation of PSMD2 could be associated with degradation of ER $\beta$ protein in endometriotic lesions by bufalin treatment. To determine the specificity of PSMD2-mediated ER $\beta$ degradation, mammalian expression vectors for $E R \alpha$, full-length $S R C-1$ and SRC-1 isoform were also cotransfected into $\mathrm{HeLa}$ cells along with expression vectors for PSMD2 and UBA7. In contrast with ER $\beta$, however, overexpression of both PSMD2 and UBA7 did not result in the degradation of ER $\alpha$ and SRC-1 isoform proteins (Fig. 4D and E). In contrast to the SRC-1 isoform, however, the full-length SRC-1 was degraded by PSMD2 but not by UBA7 (Fig. 4F). Therefore, bufalin-mediated degradation of the fulllength SRC-1 might be associated with elevation of PSMD2 in endometriotic lesions. Collectively, these results imply that bufalin disrupts the SRC-1 isoform/ER $\beta$ axis in endometriotic lesions by degrading ER $\beta$ protein through the elevation of PSMD2.
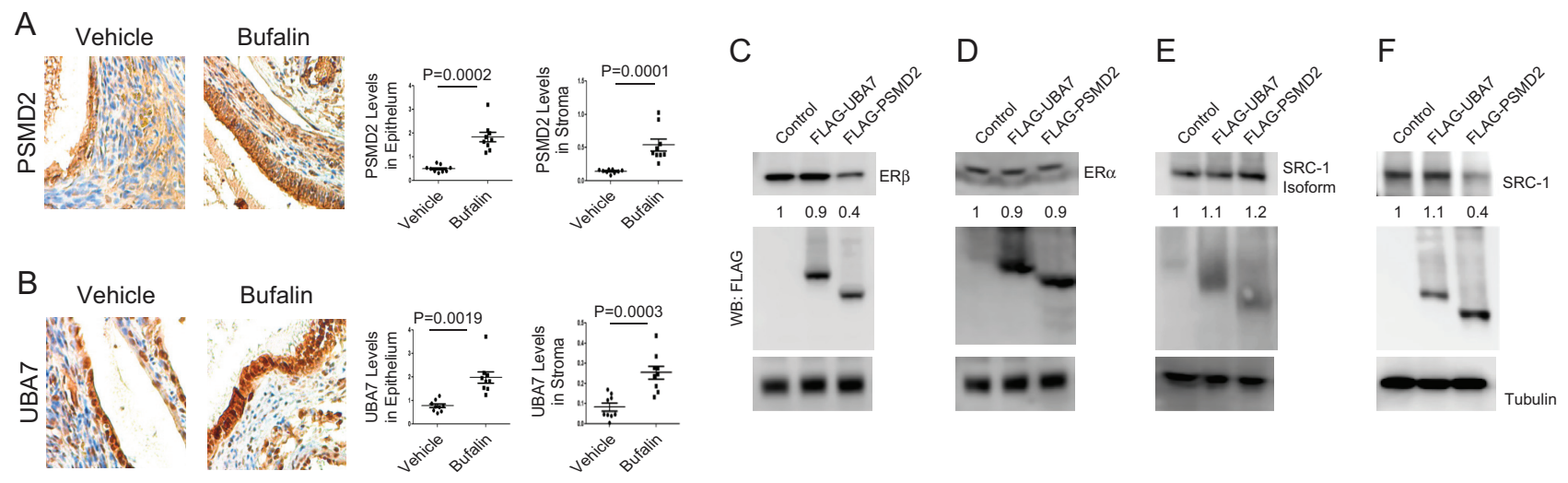

\section{Figure 4}

Bufalin degraded ER $\beta$ in endometriotic lesions via PSMD2. (A and B) Levels of PSMD2 (A) and UBA7 (B) proteins were determined in endometriotic lesions isolated from mice with endometriosis treated with bufalin $(1 \mathrm{mg} / \mathrm{kg})$ or vehicle by IHC. The expression levels of these proteins in epithelial cells and stromal cells of endometriotic lesions were quantified using ImageJ ( $n=3$ mice for each group, three independent IHC assays from each mouse). (C) To determine ER $\beta$ degradation by UBA7 or PSMD2, HeLa cells were transfected with the ER $\beta$ expression vector with the control, UBA7 and PSMD2 expression vectors. (D) To define UBA7- or PSMD2-mediated ER $\alpha$ degradation, HeLa cells were transfected with the ER $\alpha$ expression vector with the control, UBA7 and PSMD2 expression vectors. (E) To determine whether UBA7 or PSMD2 degrades the SRC-1 isoform, HeLa cells were transfected with the SRC-1 isoform expression vector with the control, UBA7 and PSMD2 expression vectors. (F) To determine whether UBA7 or PSMD2 degrades full-length SRC-1, HeLa cells were transfected with the full-length SRC-1 expression vector with the control, UBA7 and PSMD2 expression vectors. At 48th $\mathrm{h}$ after transfection, protein levels of ER $\beta$, ER $\alpha$, full-length SRC-1, SRC-1 isoform and tubulin levels were determined by Western blot analyses with their antibodies. The protein levels of UBA7 and PSMD2 were determined by Western blot analyses with FLAG antibody because the proteins had a FLAG tag in the N-terminal region. Data are presented as the means \pm S.E.M. and $P$ value (Student's $t$-test). 


\section{Bufalin treatment induced apoptosis in epithelial} cells but reduced the proliferative activity in stromal cells from endometriotic lesions

To determine the impact of bufalin-induced disruption of the SRC-1 isoform/ER $\beta$ axis in endometriosis progression, we examined the alteration of proliferation and apoptosis signaling in endometriotic lesions treated with bufalin compared to the vehicle because hyperproliferation and anti-apoptosis are closely associated with endometriosis progression and the SRC-1 isoform/ER $\beta$ axis is involved in dysregulation of apoptosis and proliferation (Salmassi et al. 2011, Han et al. 2012, 2015, Pellegrini et al. 2012). To determine the proliferative activity in endometriotic lesions, Ki-67 levels were determined by IHC (Fig. 5A). Proliferation in the epithelial compartment of endometriotic lesions was not significantly reduced by bufalin treatment (Fig. 5B). However, bufalin reduced the levels of Ki-67 by $62.5 \%(P=0.0032)$ in the stromal compartment of endometriotic lesions compared to the vehicle (Fig. 5C). Therefore, the bufalin treatment significantly reduced the proliferation of endometrial stromal cells but not that of epithelial cells from endometriotic lesions.

In addition to proliferation, we next examined apoptosis signaling by determining the levels of the active form of caspase 3 (Fig. 5D). Bufalin treatment increased the levels of the active form of caspase 3 by 9.8 -fold $(P=0.012)$ in epithelial cells from endometriotic lesions compared to the vehicle (Fig. 5E). In contrast with epithelial cells, however, the active form of caspase 3 was not detected in stromal cells in endometriotic lesions treated with bufalin and vehicle (Fig. 5F). In addition to the active form of caspase 3 , the TUNEL assay also revealed that compared with the vehicle, the bufalin treatment increased the number of TUNEL-positive cells in epithelial cells of the endometriotic lesions (Fig. 5G and $\mathrm{H}$ ). In contrast with epithelial cells, however, bufalin, compared with the vehicle, did not elevate TUNELpositive cells in stromal cells of endometriotic lesions (Fig. 5I). Collectively, bufalin treatment is associated with elevation of apoptosis signaling in epithelial cells and reduction of proliferation of stromal cells from endometriotic lesions.
A
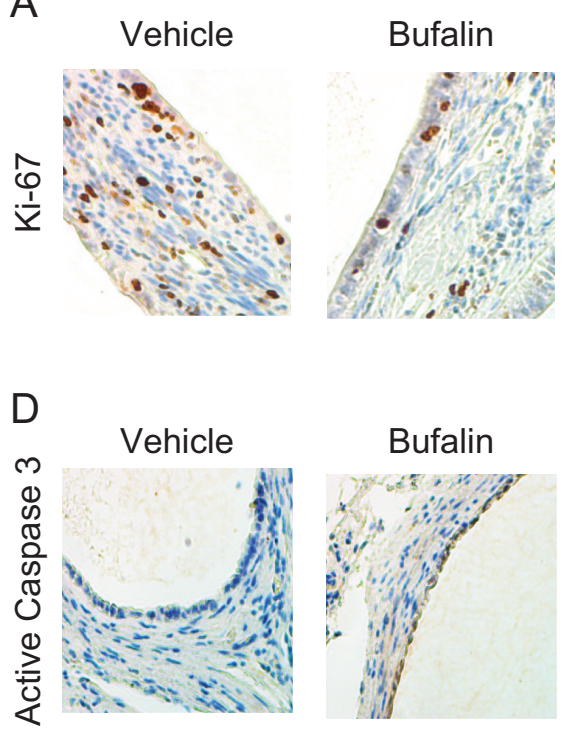

G

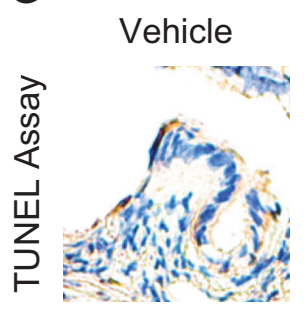

Bufalin

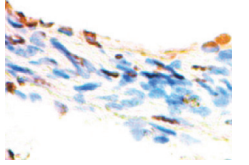

B

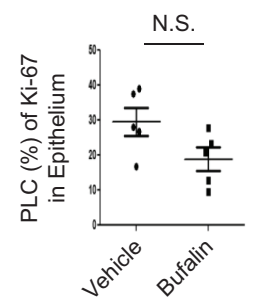

E

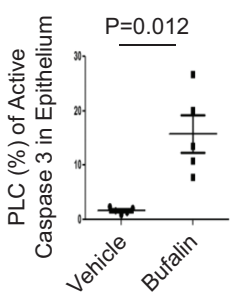

$\mathrm{H}$

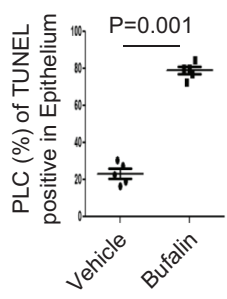

C

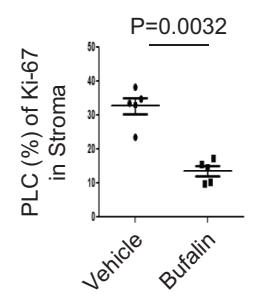

$\mathrm{F}$

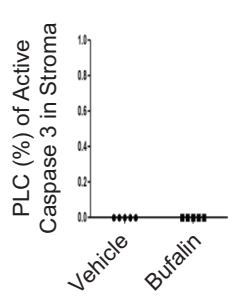

I

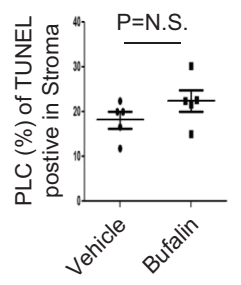

Figure 5

Bufalin induced the apoptosis and reduced the proliferation in endometriotic lesions. (A, B and C) Levels of $\mathrm{Ki}-67$ in endometriotic lesions isolated from mice with endometriosis treated with bufalin $(1 \mathrm{mg} / \mathrm{kg}$ ) and vehicle using IHC (A). The levels of Ki67 in epithelial (B) and stromal cells (C) from endometriotic lesions in Panel A were quantified by ImageJ ( $n=5$ mice for each group). (D, E and F) Levels of the active form of caspase 3 protein (D) in epithelial (E) and stromal cells (F) from endometriotic lesions treated with bufalin $(1 \mathrm{mg} / \mathrm{kg})$ or vehicle were determined using IHC and then quantified using Image $(n=5$ mice for each group). (G, $H$ and $I$ ) The number of TUNEL-positive cells $(G)$ in epithelial $(H)$ and stromal cells (I) from endometriotic lesions treated with bufalin $(1 \mathrm{mg} / \mathrm{kg})$ or vehicle were determined using IHC and then quantified using ImageJ ( $n=5$ mice for each group). Data are presented as the means \pm S.E.M. and $P$ value (Student's $t$-test). 


\section{Bufalin treatment induced the pyroptosis signaling} in stromal cells of endometriotic lesions

In addition to antiapoptosis, alteration of inflammatory signaling has an essential role in endometriosis progression. Therefore, we next examined whether inflammatory signaling is altered in endometriotic lesions by bufalin treatment. Interestingly, bufalin treatment, compared with the vehicle, elevated the active form of IL-1 $\beta$ by 5.1 -fold $(P=0.0001)$ in stromal cells but not in epithelial cells (Fig. 6A, B and C). The elevation of the active form of IL- $1 \beta$ is associated with the progression of pyroptosis (Ying \& Padanilam 2016), and caspase I is associated with progression of pyroptosis induced by the active form of IL-1 $\beta$ (Miao et al. 2011). Therefore, we next determined the levels of caspase I in endometriotic lesions treated with bufalin vs vehicle. In addition to the active form of IL-1 $\beta$, IHC revealed that the levels of caspase 1 were elevated by 2.9 -fold $(P=0.0015)$ in stromal cells, but not in epithelial cells, from bufalin-treated endometriotic lesions compared to the vehicle-treated lesions (Fig. 6D, E and F). Therefore, bufalin treatment might be associated with elevated signaling of the active form of IL-1 $\beta$ by activating the pyroptosis signaling in stromal compartments of endometriotic lesions.

\section{Bufalin treatment induced endoplasm reticulum stress (ERS) in endometriotic lesions}

Pyroptosis elevates the levels of the active form of IL-1 $\beta$, and then the increased active form of IL-1 $\beta$ promotes ERS signaling (Verma \& Datta 2010, Liu et al. 2015).

A
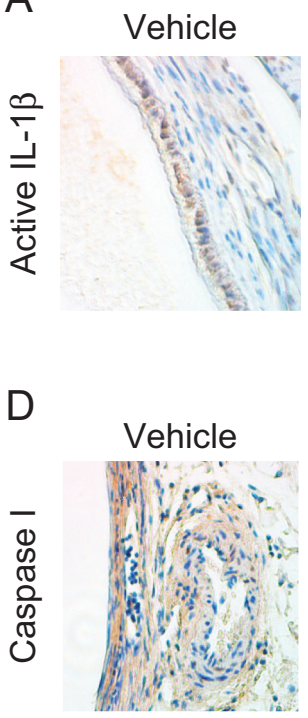

Bufalin
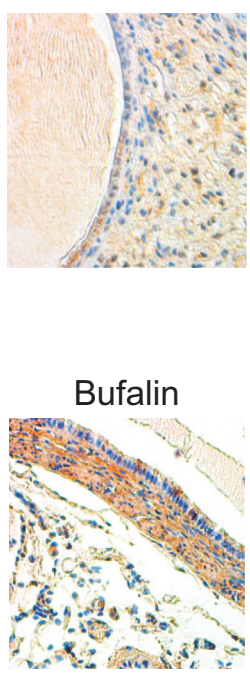

B
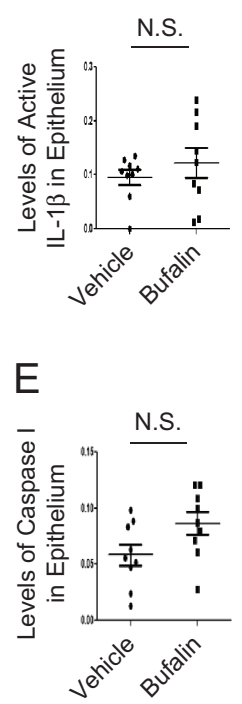

Based on these observations, we examined the levels of ERS markers, such as PKR-like ER kinase (PERK), protein disulfide isomerase (PDI) and $\mathrm{BiP}$, in endometriotic lesions treated with bufalin (Oslowski \& Urano 2011). Compared to the vehicle, bufalin treatment elevated the expression levels of PERK by 9.1-fold ( $P=0.0001)$ in epithelial cells from endometriotic lesions (Fig. 7A and B). In addition to the epithelial compartment, bufalin also increased PERK levels in stromal cells from endometriotic lesions by 4.1-fold ( $P=0.0001)$ (Fig. 7C).

The PDI levels were also elevated in epithelial cells (by 4.2-fold, $P=0.0015$ ) and stromal cells (by 2.9fold, $P=0.0001)$ in endometriotic lesions treated with bufalin compared with the vehicle (Fig. 7D, E and F). Levels of BiP were elevated by 4.6 -fold $(P=0.003)$ in epithelial cells from endometriotic lesions treated with bufalin compared with the vehicle (Fig. 7G and H). The bufalin treatment also elevated BiP levels (by 2.1-fold, $P=0.015$ ) in stromal cells from endometriotic lesions by bufalin compared with the vehicle (Fig. 7I). Therefore, bufalin treatment mainly stimulates ERS signaling in endometriotic lesions.

\section{Bufalin treatment did not impair normal uterine function of mice without endometriosis}

Our observations revealed that bufalin treatment elevated apoptosis, pyroptosis and ERS signaling and reduced the proliferation in endometriotic lesions. These observations raised the question, what is the effect of bufalin in normal uteri? To address this question, normal C57BL/6J mice were treated with bufalin (1 mg/kg for 21 days) and

C

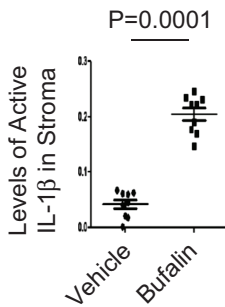

\section{Figure 6}

Bufalin induced the pyroptosis signaling in endometriotic lesions. (A, B and C) Levels of the active form of IL-1 $\beta$ in endometriotic lesions isolated from mice with endometriosis treated with bufalin $(1 \mathrm{mg} / \mathrm{kg})$ and vehicle using IHC (A). The levels of the active form of IL- $1 \beta$ in epithelial (B) and stromal cells (C) from endometriotic lesions in Panel A were quantified by ImageJ

F

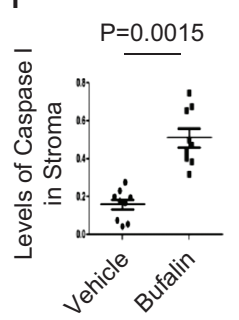
( $n=3$ mice for each group, three independent IHC assays for each mouse). (D, E and F) Levels of caspase 1 protein (D) in epithelial (E) and stromal cells (F) from endometriotic lesions treated with bufalin $(1 \mathrm{mg} / \mathrm{kg})$ or vehicle were determined using IHC and then quantified using Image $(n=3$ mice for each group, three independent IHC assays for each mouse). Data are presented as the means \pm S.E.M. and $P$ value (Student's $t$-test). 


\begin{tabular}{l|l|l|c|c|}
\hline $\begin{array}{l}\text { Journal of } \\
\text { Endocrinology }\end{array}$ & YJCho, J E Lee et al. & $\begin{array}{l}\text { Bufalin suppresses } \\
\text { endometriosis }\end{array}$ & $\mathbf{2 3 7 : 3}$ & $\mathbf{2 6 4}$ \\
\hline
\end{tabular}

A

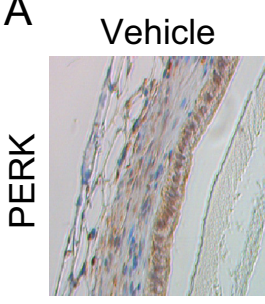

Bufalin

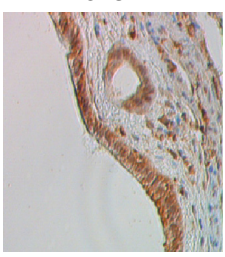

D
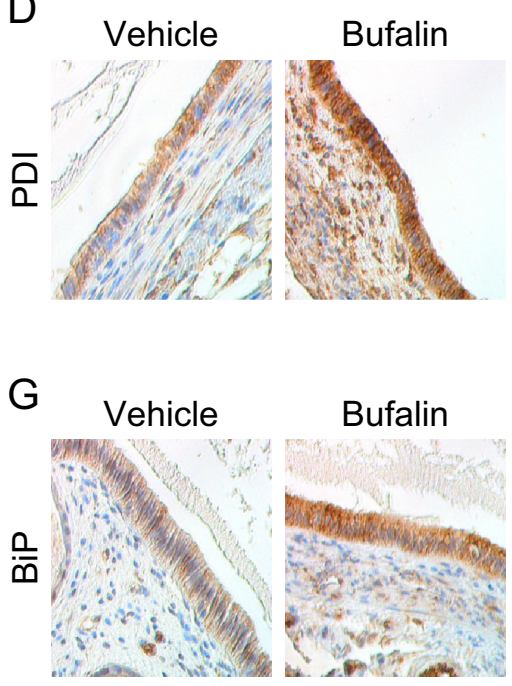

B

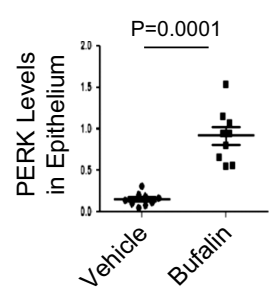

E

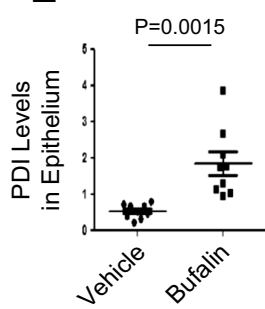

$\mathrm{H}$

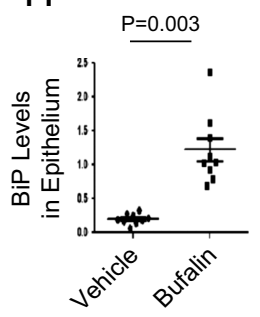

C
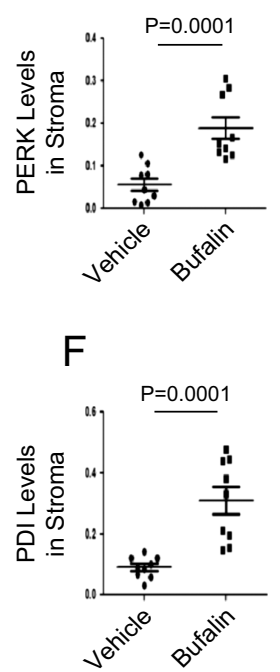

I

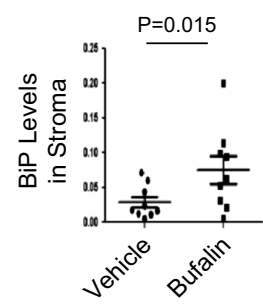

\section{Figure 7}

Bufalin induced ERS signaling in endometriotic lesions. (A, B and C) Levels of PERK protein (A) in epithelial (B) and stromal cells (C) from endometriotic lesions treated with bufalin (1 mg/ $\mathrm{kg}$ ) or vehicle were determined using IHC and then quantified using ImageJ ( $n=3$ mice for each group, three independent IHC assays for each mouse). (D, E and F) Levels of PDI protein (D) in epithelial (E) and stromal cells (F) from endometriotic lesions treated with bufalin $(1 \mathrm{mg} / \mathrm{kg})$ or vehicle were determined using IHC and then quantified using ImageJ ( $n=3$ mice for each group, three independent IHC assays for each mouse). (G, H and I) Levels of BiP protein (G) in epithelial $(\mathrm{H})$ and stromal cells $(\mathrm{I})$ from endometriotic lesions treated with bufalin ( $1 \mathrm{mg} / \mathrm{kg}$ ) or vehicle were determined using IHC and then quantified using ImageJ ( $n=3$ mice for each group, three independent IHC assays for each mouse). Data are presented as the means \pm S.E.M. and $P$ value (Student's $t$-test). vehicle as the control. IHC with Ki-67 antibody revealed that compared to the vehicle, the bufalin treatment did not reduce the proliferation activity in uteri (Fig. 8A). In addition to proliferation, the level of the active form of caspase 3 was not elevated in uteri by bufalin treatment compared to the vehicle (Fig. 8B). IHC with the active form of IL-1 $\beta$ also revealed that the pyroptosis signaling was not elevated in uteri by bufalin treatment compared to the vehicle (Fig. 8C).

To further validate the effect of bufalin on normal uterine function, we determined the fertility of female mice treated with bufalin $(1 \mathrm{mg} / \mathrm{kg})$ for 21 days. The female mouse fertility assay revealed that compared with vehicle treatment, bufalin treatment did not reduce the reproductive activity in female mice (Fig. 8D). In our hands, therefore, the 21 -day bufalin treatment $(1 \mathrm{mg} / \mathrm{kg})$ did not disrupt the fertility of female mice.

\section{Working model for bufalin-mediated endometriosis suppression}

Based on our results, we propose a model for bufalininduced suppression of endometriosis progression (Fig. 9). Bufalin degrades ER $\beta$ protein by elevating PSMD2 and hyperactivates SRC-1 isoform function in endometriotic lesions. This disruption of the bufalin-induced SRC-1 isoform/ER $\beta$ axis is associated with activation of apoptosis signaling in epithelial cells and reduces the proliferation of stromal cells. In addition, bufalin treatment stimulates the pyroptosis in stromal cells and then elevates ERS signaling in endometriotic lesions. These multiple cellular dysregulations by bufalin treatment in endometriotic lesions cause the suppression of endometriosis progression.

\section{Conclusion}

Bufalin has been known as a traditional oriental medicine and used for cancer treatment because it induces apoptosis in cancer cells (Takai et al. 2012). In addition to cancer cells, bufalin also induces apoptosis and G0/G1 cell cycle arrest in endometriotic stromal cells in vitro (Nasu et al. 2005). However, more detailed studies have not been conducted to evaluate whether bufalin can be employed as an alternative medicine for endometriosis treatment. Bufalin inhibits SRC-1 and SRC-3 functions by degrading their protein levels and inhibiting their intrinsic transcriptional activities in various cancer cells 


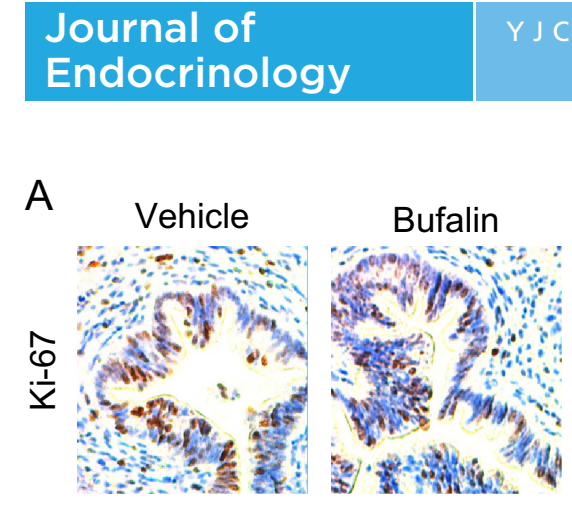

\section{A}
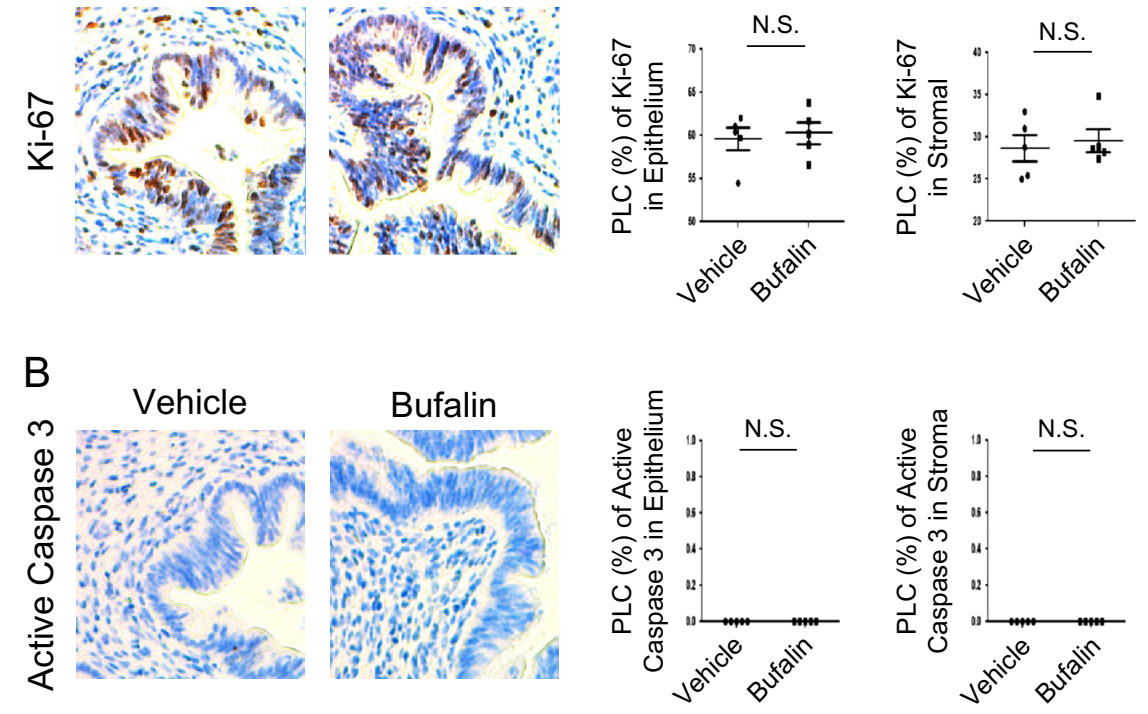

\section{Figure 8}

Bufalin did not impair the normal uterine function. (A) Levels of Ki-67 in endometriotic lesions isolated from mice treated with bufalin $(1 \mathrm{mg} / \mathrm{kg})$ and vehicle using IHC. The levels of $\mathrm{Ki}-67$ in epithelial and stromal cells from uteri in
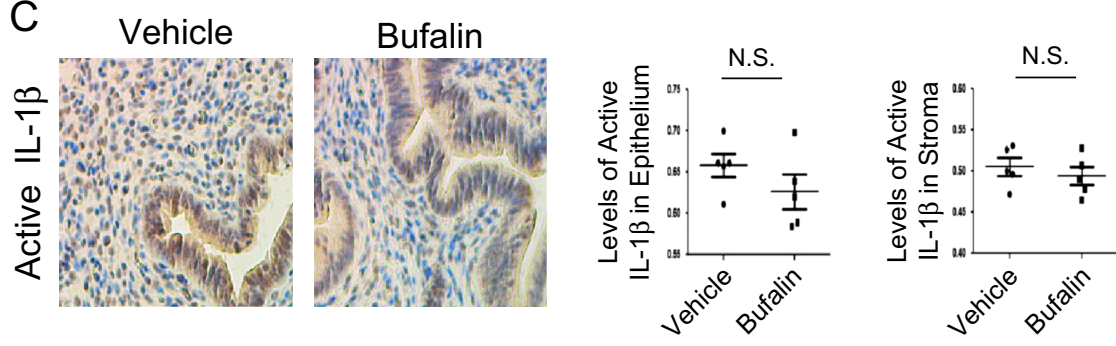
Panel A were quantified by ImageJ ( $n=5$ mice for each group). (B) Levels of the active form of caspase 3 protein in epithelial and stromal cells from uteri treated with bufalin $(1 \mathrm{mg} / \mathrm{kg})$ or vehicle were determined using IHC and then quantified using ImageJ ( $n=5$ mice for each group). (C) Levels of the active form of IL- $1 \beta$ in epithelial and stromal cells from uteri treated with bufalin $(1 \mathrm{mg} / \mathrm{kg})$ or vehicle were determined using IHC and then quantified using Image $(n=5$ mice for each group). (D) The litter size per C57BL/6J female mouse was determined after 21-day treatment with bufalin $(1 \mathrm{mg} / \mathrm{kg})$ and vehicle. Data are presented as the means \pm S.E.M. and $P$ value (Student's $t$-test).

(Wang et al. 2014). However, bufalin hyperactivates the SRC-1 isoform function, unlike that of full-length SRC-1, in endometriotic lesions. Since the SRC-1 isoform has an essential role in endometriosis progression, further activation of the SRC-1 isoform in endometriotic lesions might stimulate endometriosis progression. However, the bufalin-induced hyperactivation of the SRC-1 isoform activity suppressed the growth of endometriotic lesions compared to that of the vehicle. How we can address this discrepancy? The first explanation is that the molecular effects of bufalin on the SRC- 1 isoform are quite similar to those of another newly discovered small molecule named MCB613. MCB613 was identified as an SRC small molecule stimulator because treatment with MCB613 stimulated the transcriptional activity of SRC and markedly induced ERS coupled with the generation of reactive oxygen species to suppress the growth of cancer cells (Wang et al. 2015). Therefore, over-stimulating the
SRC oncogenic program can be an effective strategy to kill cancer cells. In the same context, therefore, over-stimulating the endometriosis-promoting SRC-1 isoform using bufalin could kill endometriotic lesions by promoting ERS induced by pyroptosis, similar to MCB613. Therefore, bufalin is an activator of the SRC-1 isoform, whereas it acts as an inhibitor against full-length SRC-1. The second explanation is that bufalin treatment degrades ER $\beta$ in endometriotic lesions. Our previous study revealed that overexpression of the SRC-1 isoform in IHEECs prevented TNF $\alpha$-induced apoptosis because IHEECs express ER $\beta$ (Han et al. 2012). Similar to SRC-1 isoform overexpression, bufalin treatment increased the SRC-1 isoform level and its transcriptional activity in endometriotic lesions. However, bufalin treatment suppressed the growth of endometriotic lesions because ER $\beta$ levels were reduced in endometriotic lesions. To prevent apoptosis in endometriotic lesions, both the 
Bufalin

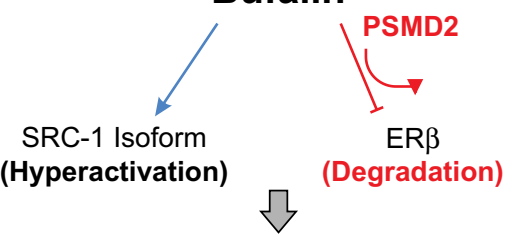

Disruption of SRC-1 Isoform/ER $\beta$ Axis in Endometriotic Lesions

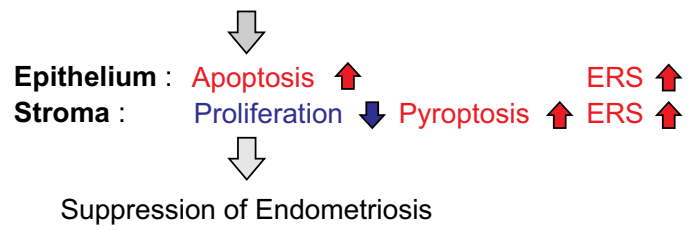

\section{Figure 9}

The working model for bufalin-mediated suppression of endometriosis progression. Bufalin hyperactivated the SRC- 1 isoform and degraded ER $\beta$ in endometriotic lesion to disrupt the SRC-1 isoform/ER $\beta$ axis. This disruption of the SRC-1 isoform/ER $\beta$ axis stimulated apoptosis in epithelial cells and reduced proliferation in stromal cells of endometriotic lesions. In addition, bufalin activated pyroptosis in stromal cells and enhanced ERS in endometriotic lesions. The alteration of these cellular pathways should suppress endometriosis progression by bufalin.

SRC-1 isoform and ER $\beta$ axis are required because the SRC-1 isoform/ER $\beta$ complex interacts with the apoptosis machinery in endometriotic lesions (Han et al. 2015). Even though bufalin elevated SRC-1 isoform function in endometriotic lesions, it did not prevent apoptosis in endometriotic lesions without ER $\beta$ and then reactivated apoptosis signaling.

In addition to the SRC-1 isoform, bufalin treatment also impaired endometriosis-stimulating ER $\beta$ signaling in endometriotic lesions by degrading ER $\beta$ protein. ER $\beta$ has been known as a key driver along with the SRC-1 isoform for endometriosis progression by preventing TNF $\beta$-induced apoptosis and activating inflammasomes (Monsivais et al. 2014, Han et al. 2015). Therefore, ER $\beta$ should be the best target to suppress endometriosis progression because the deactivation of ER $\beta$ could reactivate TNFo-induced apoptosis signaling only in endometriotic lesions to suppress their growth. Therefore, bufalin significantly reduced ER $\beta$ levels in endometriotic lesions and then reactivated apoptosis signaling in epithelial cells from endometriotic lesions to suppress the endometriosis progression. To degrade ER $\beta$ protein, bufalin treatment elevated levels of PSMD2 in endometriotic lesions. PSMD2 is a component of the $19 \mathrm{~S}$ regulatory component and is responsible for substrate recognition and binding. Interestingly, the elevation of PSMD2 levels drives the progression of various human diseases. In lung cancer, for example, elevated levels of PSMD2 and its gene signature are associated with acquisition of the metastatic phenotype and a poor prognosis because knockdown of PSMD2 decreases proteasome activity and induces growth inhibition and apoptosis in lung cancer cell lines (Matsuyama et al. 2011). Consistent with the cancer progression, proteasome components also have a crucial role in endometriosis progression because the proteasome inhibitor bortezomib suppresses endometriosis progression in a rat endometriosis model (Celik et al. 2008). In contrast with this finding, however, the bufalin-induced elevation of PSMD2 suppresses the growth of endometriotic lesions. In addition to survival functions, the proteasome also has an essential role in cell death signaling (Vacca et al. 2007). In endometriotic tissues, therefore, PSMD2 specifically recognizes ER $\beta$, an essential endometriosis driver, and then degrades it to suppress the ER $\beta$-regulated gene signature that is required for endometriosis progression. Interestingly, PSMD2 did not degrade ER $\alpha$ protein. ER $\alpha$ has critical roles in estrogen target tissues in addition to endometriosis progression, and estrogen deficiency affects different tissues, resulting in an increase in various diseases such as osteoporosis or cardiovascular diseases (Valera et al. 2015). The side effects of current endometriosis treatment are partly due to the inhibition of ER $\alpha$ signaling in these estrogen target tissues. Therefore, the bufalin/PSMD2/ER $\beta$ pathway should improve the specificity of endometriosis treatment and reduce side effects of the inhibition of ER $\alpha$ signaling by the current estrogen depletion therapy.

The disruption of the SRC-1 isoform/ER $\beta$ axis by bufalin stimulates both pyroptosis and apoptosis signaling in endometriotic lesions. At first, this observation confused us because two different types of cell death signaling occurred in endometriotic lesions at the same time. However, IHC analyses revealed that the two different cell death signaling pathways are detected in different cellular compartments of endometriotic lesions. For example, activation of pyroptosis and apoptosis is detected in stromal and epithelial cells of endometriotic lesions, respectively. Pyroptosis, or caspase 1-dependent cell death, is known as inflammatory cell death signaling and is initiated by various pathological stimuli, such as stroke, heart attack or cancer (Bergsbaken et al. 2009). However, the role of pyroptosis in endometriosis progression has not been reported. Here, we revealed that bufalin induced pyroptosis in the stromal compartments of endometriotic lesions by elevating the active form of IL- $1 \beta$ and caspase 1 in stromal cells. IL- $1 \beta$ signaling has been known as a double-edged sword because the elevation of the active form of IL- $1 \beta$ results in proliferative activity in 
certain cases but also induces cell death signaling in other cases (Kolb et al. 2014). For survival, for example, ER $\beta$ activated caspase 1 activity in inflammasomes and then increased the active form of IL- $1 \beta$ levels in endometriotic lesions to activate cell adhesion and proliferative activity in ectopic lesions (Han et al. 2015). However, bufalin treatment hyperelevated the levels of the active form of IL- $\beta$ in the stromal compartments of endometriotic lesions compared to the vehicle-treated endometriotic lesions. Hyperactivating IL-1 $\beta$ signaling induced ERS, resulting in cell death in human pancreatic cells (Verma \& Datta 2010). Therefore, bufalin treatment elevates hyper-releasing active forms of IL- $1 \beta$ from pyroptotic stromal cells and enhances ERS in endometriotic lesions to effectively suppress the growth of endometriotic lesions along with activation of apoptosis in epithelial cells of endometriotic lesions.

It appears that bufalin itself may not be an ideal drug for endometriosis. Bufalin belongs to the bufadienolide group, and bufadienolides are known for having deleterious cardiovascular side effects due to their inhibition of the transport enzyme $\mathrm{Na}^{+} / \mathrm{K}^{+}-$ adenosine triphosphatase ( $\mathrm{Xu}$ et al. 2016). Despite this known cytotoxic property of bufadienolides, they have been used to treat cardiovascular and kidney diseases (Puschett et al. 2010). Chronic treatment with a low dose of bufadienolides has been proven to be effective in certain instances, causing little to no side effects (Panesar 1992, Jing et al. 1994). Our study also revealed that 21-day bufalin treatment $(1 \mathrm{mg} / \mathrm{kg})$ did not impair normal uterine function and fertility. We know, however, that bufalin has potential cardiac ion channel toxicity so it is not an ideal candidate drug with which to go forward. Although the combination therapy of low-dose bufalin and other drugs could be further investigated, this study mainly points to the value of searching in the future for additional new chemicals other than bufalin that inhibit SRC function as potential therapies for endometriosis.

\section{Declaration of interest}

The authors declare that there is no conflict of interest that could be perceived as prejudicing the impartiality of the research reported.

\section{Funding}

This work was supported by grants from the US National Eunice Kennedy Shriver National Institute of Child Health and Human Development (NICHD, R01HD082786 and R01HD008188 to B W O), National Institute of Diabetes and Digestive and Kidney Diseases (NIDDK, U24 DK097748 Pilot Grant to $\mathrm{S} J \mathrm{H}$ ) and Mike Hogg Foundation to $\mathrm{S} J \mathrm{H}$.

\section{Acknowledgment}

S J H led the entire project. S J H and B W O evaluated all data. S J H, Y J C, $\mathrm{J} L$ and $M J P$ designed and performed the experiments. S J H, Y J C and J L wrote the manuscript. Yeon Jean Cho and Jiyeun Lee equally contributed to this work.

\section{References}

Bedaiwy MA, Alfaraj S, Yong P \& Casper R 2017 New developments in the medical treatment of endometriosis. Fertility and Sterility 107 555-565. (https://doi.org/10.1016/j.fertnstert.2016.12.025)

Bergsbaken T, Fink SL \& Cookson BT 2009 Pyroptosis: host cell death and inflammation. Nature Reviews Microbiology 7 99-109. (https://doi. org/10.1038/nrmicro2070)

Bono Y, Kyo S, Takakura M, Maida Y, Mizumoto Y, Nakamura M, Nomura K, Kiyono T \& Inoue M 2012 Creation of immortalised epithelial cells from ovarian endometrioma. British Journal of Cancer 106 1205-1213. (https://doi.org/10.1038/bjc.2012.26)

Brilhante AV, Augusto KL, Portela MC, Sucupira LC, Oliveira LA, Pouchaim AJ, Nobrega LR, Magalhaes TF \& Sobreira LR 2017 Endometriosis and ovarian cancer: an integrative review (endometriosis and ovarian cancer). Asian Pacific Journal of Cancer Prevention 18 11-16. (https://doi.org/10.22034/ APJCP.2017.18.1.11)

Bulun SE 2009 Endometriosis. New England Journal of Medicine 360 268-279. (https://doi.org/10.1056/NEJMra0804690)

Bulun SE, Cheng YH, Pavone ME, Yin P, Imir G, Utsunomiya H, Thung S, Xue Q, Marsh EE, Tokunaga H,et al. 2010 17Beta-hydroxysteroid dehydrogenase- 2 deficiency and progesterone resistance in endometriosis. Seminars in Reproductive Medicine 28 44-50. (https:// doi.org/10.1055/s-0029-1242992)

Celik O, Hascalik S, Elter K, Tagluk ME, Gurates B \& Aydin NE 2008 Combating endometriosis by blocking proteasome and nuclear factorkappaB pathways. Human Reproduction 23 2458-2465. (https://doi. org/10.1093/humrep/den246)

Cummings AM \& Metcalf JL 1995 Induction of endometriosis in mice: a new model sensitive to estrogen. Reproductive Toxicology 9 233-238. (https://doi.org/10.1016/0890-6238(95)00004-T)

Ebert AD, Bartley J \& David M 2005 Aromatase inhibitors and cyclooxygenase-2 (COX-2) inhibitors in endometriosis: new questions - old answers? European Journal of Obstetrics and Gynecology and Reproductive Biology 122 144-150. (https://doi.org/10.1016/j. ejogrb.2005.04.017)

Farland LV, Tamimi RM, Eliassen AH, Spiegelman D, Hankinson SE, Chen WY \& Missmer SA 2016 Laparoscopically confirmed endometriosis and breast cancer in the Nurses' Health Study II. Obstetrics and Gynecology 128 1025-1031. (https://doi.org/10.1097/ AOG.0000000000001684)

Farland LV, Lorrain S, Missmer SA, Dartois L, Cervenka I, Savoye I, Mesrine S, Boutron-Ruault MC \& Kvaskoff M 2017 Endometriosis and the risk of skin cancer: a prospective cohort study. Cancer Causes and Control 28 1011-1019. (https://doi.org/10.1007/s10552017-0939-2)

Goenka L, George M \& Sen M 2017 A peek into the drug development scenario of endometriosis - a systematic review. Biomedicine and Pharmacotherapy 90 575-585. (https://doi.org/10.1016/j. biopha.2017.03.092)

Han SJ, Jeong J, Demayo FJ, Xu J, Tsai SY, Tsai MJ \& O’Malley BW 2005 Dynamic cell type specificity of SRC-1 coactivator in modulating uterine progesterone receptor function in mice. Molecular and Cellular Biology 25 8150-8165. (https://doi.org/10.1128/MCB.25.18.81508165.2005)

Han SJ, Hawkins SM, Begum K, Jung SY, Kovanci E, Qin J, Lydon JP, DeMayo FJ \& O'Malley BW 2012 A new isoform of steroid 
receptor coactivator-1 is crucial for pathogenic progression of endometriosis. Nature Medicine 18 1102-1111. (https://doi. org/10.1038/nm.2826)

Han SJ, Jung SY, Wu S, Hawkins SM, Park MJ, Kyo S, Qin J, Lydon JP, Tsai SY, Tsai MJ,et al. 2015 Estrogen receptor $\beta$ modulates apoptosis complexes and the inflammasome to drive the pathogenesis of endometriosis. Cell 163 960-974. (https://doi.org/10.1016/j. cell.2015.10.034)

Hirata T, Osuga Y, Takamura M, Saito A, Hasegawa A, Koga K, Yoshino O, Hirota Y, Harada M \& Taketani Y 2011 Interleukin-17F increases the secretion of interleukin- 8 and the expression of cyclooxygenase 2 in endometriosis. Fertility and Sterility 96 113-117. (https://doi. org/10.1016/j.fertnstert.2011.04.060)

Jing Y, Ohizumi H, Kawazoe N, Hashimoto S, Masuda Y, Nakajo S, Yoshida T, Kuroiwa Y \& Nakaya K 1994 Selective inhibitory effect of bufalin on growth of human tumor cells in vitro: association with the induction of apoptosis in leukemia HL-60 cells. Japanese Journal of Cancer Research 85 645-651. (https://doi. org/10.1111/j.1349-7006.1994.tb02408.x)

Kolb R, Liu GH, Janowski AM, Sutterwala FS \& Zhang W 2014 Inflammasomes in cancer: a double-edged sword. Protein and Cell $\mathbf{5}$ 12-20. (https://doi.org/10.1007/s13238-013-0001-4)

Krikun G, Mor G, Alvero A, Guller S, Schatz F, Sapi E, Rahman M, Caze R, Qumsiyeh M \& Lockwood CJ 2004 A novel immortalized human endometrial stromal cell line with normal progestational response. Endocrinology 145 2291-2296. (https://doi.org/10.1210/ en.2003-1606)

Kyo S, Nakamura M, Kiyono T, Maida Y, Kanaya T, Tanaka M, Yatabe N \& Inoue M 2003 Successful immortalization of endometrial glandular cells with normal structural and functional characteristics. American Journal of Pathology 163 2259-2269. (https://doi.org/10.1016/S00029440(10)63583-3)

Lamp M, Peters M, Reinmaa E, Haller-Kikkatalo K, Kaart T, Kadastik U, Karro H, Metspalu A \& Salumets A 2011 Polymorphisms in ESR1, ESR2 and HSD17B1 genes are associated with fertility status in endometriosis. Gynecological Endocrinology 27 425-433. (https://doi. org/10.3109/09513590.2010.495434)

Liu Z, Zhao N, Zhu H, Zhu S, Pan S, Xu J, Zhang X, Zhang Y \& Wang J 2015 Circulating interleukin-1beta promotes endoplasmic reticulum stress-induced myocytes apoptosis in diabetic cardiomyopathy via interleukin-1 receptor-associated kinase-2. Cardiovascular Diabetology 14 125. (https://doi.org/10.1186/s12933-015-0288-y)

Matsuyama Y, Suzuki M, Arima C, Huang QM, Tomida S, Takeuchi T, Sugiyama R, Itoh Y, Yatabe Y, Goto H,et al. 2011 Proteasomal non-catalytic subunit PSMD2 as a potential therapeutic target in association with various clinicopathologic features in lung adenocarcinomas. Molecular Carcinogenesis 50 301-309. (https://doi. org/10.1002/mc.20632)

McLean AC, Valenzuela N, Fai S \& Bennett SA 2012 Performing vaginal lavage, crystal violet staining, and vaginal cytological evaluation for mouse estrous cycle staging identification. Journal of Visualized Experiments e4389. (https://doi.org/10.3791/4389)

Miao EA, Rajan JV \& Aderem A 2011 Caspase-1-induced pyroptotic cell death. Immunological Reviews 243 206-214. (https://doi.org/10.1111/ j.1600-065X.2011.01044.x)

Monsivais D, Dyson MT, Yin P, Coon JS, Navarro A, Feng G, Malpani SS, Ono M, Ercan CM, Wei JJ,et al. 2014 ERbeta- and prostaglandin E2-regulated pathways integrate cell proliferation via Ras-like and estrogen-regulated growth inhibitor in endometriosis. Molecular Endocrinology 28 1304-1315. (https://doi.org/10.1210/ me.2013-1421)

Nasu K, Nishida M, Ueda T, Takai N, Bing S, Narahara H \& Miyakawa I 2005 Bufalin induces apoptosis and the G0/G1 cell cycle arrest of endometriotic stromal cells: a promising agent for the treatment of endometriosis. Molecular Human Reproduction 11 817-823. (https:// doi.org/10.1093/molehr/gah249)
Oslowski CM \& Urano F 2011 Measuring ER stress and the unfolded protein response using mammalian tissue culture system. Methods in Enzymology 490 71-92. (https://doi.org/10.1016/B978-0-12-3851147.00004-0)

Panesar NS 1992 Bufalin and unidentified substance(s) in traditional Chinese medicine cross-react in commercial digoxin assay. Clinical Chemistry 38 2155-2156.

Pellegrini C, Gori I, Achtari C, Hornung D, Chardonnens E, Wunder D, Fiche M \& Canny GO 2012 The expression of estrogen receptors as well as GREB1, c-MYC, and cyclin D1, estrogen-regulated genes implicated in proliferation, is increased in peritoneal endometriosis. Fertility and Sterility 98 1200-1208. (https://doi.org/10.1016/j. fertnstert.2012.06.056)

Poole EM, Lin WT, Kvaskoff M, De Vivo I, Terry KL \& Missmer SA 2017 Endometriosis and risk of ovarian and endometrial cancers in a large prospective cohort of U.S. nurses. Cancer Causes and Control $\mathbf{2 8}$ 437-445. (https://doi.org/10.1007/s10552-017-0856-4)

Puschett JB, Agunanne E \& Uddin MN 2010 Emerging role of the bufadienolides in cardiovascular and kidney diseases. American Journal of Kidney Diseases 56 359-370. (https://doi.org/10.1053/j. ajkd.2010.01.023)

Sacco K, Portelli M, Pollacco J, Schembri-Wismayer P \& Calleja-Agius J 2012 The role of prostaglandin E2 in endometriosis. Gynecological Endocrinology 28 134-138. (https://doi.org/10.3109/09513590.2011. 588753)

Saji S, Jensen EV, Nilsson S, Rylander T, Warner M \& Gustafsson JA 2000 Estrogen receptors alpha and beta in the rodent mammary gland. PNAS 97 337-342. (https://doi.org/10.1073/pnas.97.1.337)

Salmassi A, Acar-Perk B, Schmutzler AG, Koch K, Pungel F, Jonat W \& Mettler L 2011 Apoptosis resistance in endometriosis. Bioimpacts $\mathbf{1}$ 129-134. (https://doi.org/10.5681/bi.2011.017)

Takai N, Kira N, Ishii T, Yoshida T, Nishida M, Nishida Y, Nasu K \& Narahara H 2012 Bufalin, a traditional oriental medicine, induces apoptosis in human cancer cells. Asian Pacific Journal of Cancer Prevention 13 399-402. (https://doi.org/10.7314/ APJCP.2012.13.1.399)

Vacca RA, Valenti D, Bobba A, de Pinto MC, Merafina RS, De Gara L, Passarella S \& Marra E 2007 Proteasome function is required for activation of programmed cell death in heat shocked tobacco BrightYellow 2 cells. FEBS Letters 581 917-922. (https://doi.org/10.1016/j. febslet.2007.01.071)

Valera MC, Gourdy P, Tremollieres F \& Arnal JF 2015 From the Women's Health Initiative to the combination of estrogen and selective estrogen receptor modulators to avoid progestin addition. Maturitas 82 274-277. (https://doi.org/10.1016/j.maturitas.2015.07.012)

Vercellini P, Vigano P, Somigliana E \& Fedele L 2014 Endometriosis: pathogenesis and treatment. Nature Reviews Endocrinology 10 261-275. (https://doi.org/10.1038/nrendo.2013.255)

Verma G \& Datta M 2010 IL-1beta induces ER stress in a JNK dependent manner that determines cell death in human pancreatic epithelial MIA PaCa-2 cells. Apoptosis 15 864-876. (https://doi.org/10.1007/ s10495-010-0498-4)

Wang Y, Lonard DM, Yu Y, Chow DC, Palzkill TG \& O’Malley BW 2011 Small molecule inhibition of the steroid receptor coactivators, SRC-3 and SRC-1. Molecular Endocrinology 25 2041-2053. (https://doi. org/10.1210/me.2011-1222)

Wang Y, Lonard DM, Yu Y, Chow DC, Palzkill TG, Wang J, Qi R, Matzuk AJ, Song X, Madoux F,et al. 2014 Bufalin is a potent smallmolecule inhibitor of the steroid receptor coactivators SRC-3 and SRC-1. Cancer Research 74 1506-1517. (https://doi.org/10.1158/00085472.CAN-13-2939)

Wang L, Yu Y, Chow DC, Yan F, Hsu CC, Stossi F, Mancini MA, Palzkill T, Liao L, Zhou S,et al. 2015 Characterization of a steroid receptor coactivator small molecule stimulator that overstimulates cancer cells and leads to cell stress and death. Cancer Cell 28 240-252. (https:// doi.org/10.1016/j.ccell.2015.07.005) 
Xu Y, Liu X, Schwarz S, Hu L, Guo D, Gu Q \& Schwarz W 2016 Inhibitory efficacy of bufadienolides on $\mathrm{Na}(+), \mathrm{K}(+)$-pump activity versus cell proliferation. Biochemistry and Biophysics Reports 6 158-164. (https:// doi.org/10.1016/j.bbrep.2016.03.015)

Ying Y \& Padanilam BJ 2016 Regulation of necrotic cell death: p53, PARP1 and cyclophilin D-overlapping pathways of regulated necrosis?
Cellular and Molecular Life Sciences 73 2309-2324. (https://doi. org/10.1007/s00018-016-2202-5)

Zhang ZJ, Yang YK \& Wu WZ 2014 Bufalin attenuates the stage and metastatic potential of hepatocellular carcinoma in nude mice. Journal of Translational Medicine 12 57. (https://doi.org/10.1186/14795876-12-57)

Received in final form 21 March 2018

Accepted 10 April 2018

Accepted Preprint published online 10 April 2018
๑) 2018 Society for Endocrinology Published by Bioscientifica Ltd.
Printed in Great Britain 